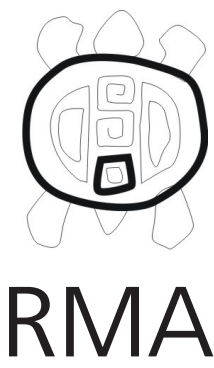

Museología

\section{Preservar, investigar y comunicar: Un caso mexicano}

\author{
María Gabriela Chaparro
}

CONICET, INCUAPA, PATRIMONIA. Facultad de Ciencias Sociales. Universidad Nacional del Centro de la Provincia de Buenos Aires. Olavarría. Buenos Aires. E-mail: chaparro@soc.unicen.edu.ar

\begin{abstract}
Resumen
En este trabajo se presentan y discuten las distintas funciones atribuidas a un museo, sobre la base del análisis de las prácticas actuales que se realizan en el Museo Nacional de Antropología de México. En un primer momento, se realizará una revisión histórica de esta institución de larga trayectoria, para evaluar, a partir de esa contextualización la preservación, primera función del museo, que incluye, conservar y coleccionar. Posteriormente será el turno de considerar las tareas de investigación, y por último, se hará un análisis del comunicar y el exhibir. El mismo no pretende poner en tela de juicio instituciones ni organismos, sino conocer y analizar el estado de situación de estas tres áreas funcionales, con el fin de evaluar las relaciones y prácticas museológicas establecidas. Lo valioso de esta clase de estudios es que brinda la posibilidad de conocer "desde adentro" un museo de la importancia y la envergadura del Museo de Antropología mexicano.
\end{abstract}

Palabras Claves: museos; preservación; investigación; comunicación; Museo Nacional de Antropología de México.

Preserve, research and comunicate: a mexican case.

\begin{abstract}
In this paper different functions attributed to the museum are presented and discussed considering the analysis of contemporary practices that have been executed at the National Museum of Anthropology of Mexico. At first place a historical revision of the institution will be analysed in order to evaluate preservation, the first function of the museum, which includes conservation and collecting. Furthermore, the study follows with the steps of researching and finally the aspects of communication and exhibiting will be analysed. This work does not seek to pass judgment on the institutions nor official organism but rather tries to know and analyse the situation of these three functional areas looking to evaluate the practices and relationships established at the museum. The relevance of this type of study resides in the possibility of knowing from inside a museum of the importance and magnitude as the National Museum of Anthropology of Mexico.
\end{abstract}

Keywords: museums; preservation; researching; communication; National Museum of Anthropology of Mexico.

En 1974 el Consejo Internacional de Museos (ICOM), órgano consultivo de la UNESCO, estableció una nueva definición de museo en su Estatuto ${ }^{1}$. En ella propone que los museos deben cumplir una serie de funciones, entre las cuales se encuentran adquirir o coleccionar, conservar, investigar, comunicar y exhibir. Estas cinco actividades tienen que perseguir tres fines bien delimitados, estudio, educación y deleite. Hacia la década del noventa, autores como Weil (1990) propusieron que las cinco funciones podían sintetizarse en tres, quedando así definidas, preservar (incluye adquirir y conservar), investigar y comunicar (exhibir y difundir). Más allá de estas diferencias nominales, el presente trabajo evalúa estas funciones en la práctica en una institución de renombre mundial como lo es el Museo Nacional de Antropología de México. Este museo (en adelante MNA)

\footnotetext{
${ }^{1}$ Artículo 2, parte I del Estatuto del Consejo Internacional de Museos.
}

presenta las "culturas" arqueológicas y etnográficas actuales del territorio mexicano. Es uno de los museos más importantes de México y de América Latina, y es un orgullo para la nacionalidad mexicana.

Para un mayor entendimiento y análisis de las actividades que actualmente realiza el MNA es necesario una comprensión de su desarrollo histórico, ya que las distintas áreas funcionales del mismo no son las mismas desde su comienzo, y sus colecciones han atravesado por una larga trayectoria. Estas últimas, han sido protagonistas de los vaivenes del proceso de conformación histórico del Estado mexicano, desde que fueron "descubiertas" hasta su actual ubicación en el edificio construido para tal fin (en 1964), localizado en el Bosque de Chapultepec. En esta primera sección del trabajo, se utilizará la información registrada a través de relevamientos bibliográficos realizados en el Archivo Histórico del MNA, en su 
biblioteca y en el archivo de la Coordinación Nacional de Museos y Exposiciones (CNMyE). La segunda parte del trabajo se centrará en el análisis de la información recolectada mediante entrevistas y observaciones de campo, realizadas por la autora en el marco de una estancia de investigación en dicho Museo.

\section{El Museo Nacional a través del tiempo}

En México, las primeras actividades vinculadas a la conservación se remontan a la época colonial. En 1790 con las obras de empedrado y reencause de aguas subterráneas en la Plaza Mayor se desenterraron dos grandes estatuas talladas (Coatlicue y la Piedra del Sol), las cuales fueron resguardadas como testimonios de la historia pasada, por orden del virrey de la Nueva España (León y Gama 1792, citado en Velasco Alonso 2009:34). A partir de ese momento, estas dos piezas (íconos del actual MNA) comenzaron un largo camino, que incluyó la exposición de las mismas en distintos lugares de la ciudad²; su ocultamiento por tratarse de piezas "monstruosas", y el deterioro de su integridad por hechos de "vandalismo"4. Hacia 1822, el incremento de las colecciones por recolecciones de viajeros y exploradores y como consecuencia del crecimiento de la infraestructura de la ciudad, llevó a que se creara el Conservatorio de Antigüedades y un Gabinete de Historia Natural en la Real y Pontificia Universidad (Solís Olguín 2004). Una década más tarde, las colecciones ya podían ser clasificadas por sus orígenes, arqueológico, histórico y natural, por lo que se crearía el primer Museo Mexicano dependiente de la Real Universidad (1831). En 1865 estas colecciones fueron trasladadas al Palacio de la Moneda conformando el Museo Público de Historia Natural, Arqueología e Historia (Rico Mansard 2008). Este traslado merece atención porque las colecciones pasaron de estar en manos del "saber erudito", bajo la órbita de una universidad católica, a depender del monopolio cultural del Estado (Morales Moreno 2008) y de esta manera pasaron a constituir el acervo de la nación mexicana (Arciniega Ávila 2008). Hasta esta fecha se puede plantear que el Museo era sólo un conjunto de intensiones y acciones para la recolección de objetos. De ahí en adelante comenzaría una nueva etapa más interesada en la conservación (Morales Moreno 1994), sin embargo, más que nunca será botín de disputas internas. Así podría interpretarse los continuos traslados que sufrió el Museo, primero al Palacio de Minería, para luego, a mediados de la década de 1870, retornar al Palacio de la Moneda.

Con el gobierno reformista de Benito Juárez, entre

\footnotetext{
2 En un primer momento, la Piedra del Sol fue empotrada en la Catedral Metropolitana, luego traslada al Palacio Moneda, mientras que la Coatlicue fue localizada en el patio interno en la Real y Pontificia Universidad.

3 La Coatlicue durante un período fue reenterrada en la Real y Pontificia Universidad.

4 Durante la ocupación norteamericana (1846-1848) la Piedra del Sol fue utilizada de blanco para las prácticas de tiro de los soldados invasores.
}

mediados de las décadas de 1860 y 1870, comenzaría a perfilarse un museo positivista, ya que a partir de esos años se realizó la primera organización de las piezas en arqueológicas o históricas y se publicaron el catálogo "científico" de las colecciones y la primera revista de divulgación, los Anales (Morales Moreno 1994:39). Esto se consolidó con el largo gobierno de Porfirio Díaz durante el cual se construyó la Galería de los Monolitos en el Palacio de la Moneda, inaugurada en 1877. Esta era la sala ${ }^{5}$ más importante del Museo Nacional, donde se encontraban las grandes esculturas de piedra, principalmente mexicas coronadas por la Piedra del Sol, la cual, hasta ese momento, se encontraba en la Catedral (Rico Mansard 2008; Velasco Alonso 2009). Es a partir de ese momento que se postula "que los grandes monolitos aztecas eran representativos de la cultura prehispánica" (Morales Moreno 1994:39). Este mismo autor (Morales Moreno 1994) propone que el Museo contribuyó a la refundación de la identidad nacional a partir de la recuperación del pasado prehispánico mediante la sacralización secular de la historia de la patria. Para esa época las colecciones arqueológicas-históricas del museo formaban parte del "patrimonio nacional" y estaban protegidas legalmente como tales. Paralelamente, el guión museográfico estaba impregnado de la versión oficial de la historia que era similar a la dictada por la Secretaría de Instrucción Pública. Por otro lado el museo comenzó a constituirse en una institución de renombre mundial, ya que desarrolló numerosas exposiciones en Europa y fue sede de congresos internacionales, esto le posibilitó "abrir fronteras a través de la exhibición de piezas arqueológicas" (Morales Moreno 1994:41). Finalmente, en 1909 en vísperas del primer centenario de la independencia se decidió realizar las primeras adaptaciones y la separación de los acervos del museo, trasladándose las colecciones de historia natural para la conformación de un museo para ese fin (Rico Mansard 2008), lo cual está enfatizando el quiebre de la misma con la historia cultural mexicana.

Durante el período revolucionario (1911-1925) el museo estuvo influenciado por Alfonso Pruneda ${ }^{6}$ y Jesús Galindo y Villa7, ambos precursores de la museología mexicana. Ellos incorporaron nuevos elementos museográficos y establecieron vínculos con otras corrientes antropológicas, las cuales les permitieron realizar las primeras críticas al museo como "almacén de cosas viejas". Por otro lado, le otorgaron al Museo una mayor identificación con la idea de "museo-ciencia-educador", con un fin claro: la formación de una cultura social. A pesar de ello, el positivismo porfiriano tuvo continuidad, principalmente en el criterio de veracidad y objetividad de la ciencia y

\footnotetext{
${ }^{5}$ Otras salas estaban congestionadas de nuevas piezas arqueológicas recuperadas en los movimientos de tierras, fruto del importante aumento de obras de infraestructura realizados en la ciudad.

${ }^{6}$ Alfonso Pruneda, rector de la Universidad Nacional de México.

7 Jesús Galindo y Villa, historiador, investigador y director del Museo Nacional.
} 
el progreso, y a su vez, el amor patrio y la búsqueda de una identidad común.

Pasada la segunda década del siglo XX, las colecciones y salas que se encontraban en la antigua Galería de los Monolitos fueron reestructuradas ${ }^{8}$ y sufrieron una reorganización, ya bajo la nueva denominación de Museo Nacional de Arqueología y Etnografía (1940) (el cual seguía ubicado en el Palacio de la Moneda) y pasaría a depender del Instituto Nacional de Antropología e Historia (INAH), fundado en el año 1939.

\section{El nuevo Museo Nacional}

Con el fuerte incremento de las colecciones arqueológicas que llegaban de todo el país, hacia mediados de siglo XX comenzó a gestarse la idea de un nuevo museo. El mismo tendría un edificio propio, diseñado especialmente para esa función, bajo la dirección del arquitecto Pedro Ramírez Vázquez y la participación de un grupo de profesionales antropólogos y arqueólogos. Este nuevo edificio estaría ubicado en el corazón del Bosque de Chapultepec, contaría con salas, depósitos, gabinetes de investigación, servicios educativos y áreas con servicios al público. Finalmente en 1964 fue inaugurado el edificio actual, cuyo diseño, de arquitectura moderna por sus materiales y sus líneas rectas, está inspirado en las construcciones mesoamericanas prehispánicas. El edificio está rodeado por una serie de jardines, recreando construcciones arqueológicas y se han instalado en ellos, esculturas originales y réplicas de estelas, templos y

8 Las colecciones históricas se envían al Museo Nacional de Historia, en el Castillo de Chapultepec (1937). edificios. En su patio central posee, como sello distintivo, un gran paraguas de $17 \mathrm{~m}$ del que cae una cortina de agua constante, y en cuya base se representan plásticamente, el México contemporáneo que emerge de sus raíces prehispánicas, los pies indígenas, la conquista y el ingreso español, posteriormente los símbolos de la independencia, la reforma y la revolución (AHMNA, Volumen 17400, año 1964, Expediente 39- fs. 117-118). En el mismo patio, pero ya por fuera de la cobertura del paraguas, se encuentra un estanque de agua, que es el "atrio" de la sala mexica (Ramírez Vázquez 2008). En este espejo se representan los cuatro elementos (agua, tierra, fuego y aire) de la naturaleza y rememora los orígenes acuáticos en el Lago Texcoco de México-Tenochtitlan (centro del imperio azteca, centro político -institucional de los Estados Unidos Mexicanos).

Las once salas de Arqueología son de grandes dimensiones y su disposición permite visitarlas en forma individual pero continua. Están ordenadas desde el punto de vista cronológico, regional y cultural. En el ala derecha se encuentran las Salas de Introducción a la Antropología, Poblamiento de América, Preclásico, Teotihuacán y Toltecas. Por su parte, en el ala izquierda, Culturas del Norte, de Occidente, Costa del Golfo, Oaxaca y Maya. Pero hay una que se destaca, la Sala Mexica, por dos cuestiones. En primer lugar, se encuentra en el centro de las dos alas, cuya entrada es distinta de las otras, por el mencionado estanque y porque posee un gran friso de entrada, grabado en mármol con la siguiente inscripción en náhuatl-español: Totenyo, Totauhca Mexica, Nuestra Gloria, nuestra fama mexica (Figura 1)

En segundo lugar, su altura es el doble de las restantes

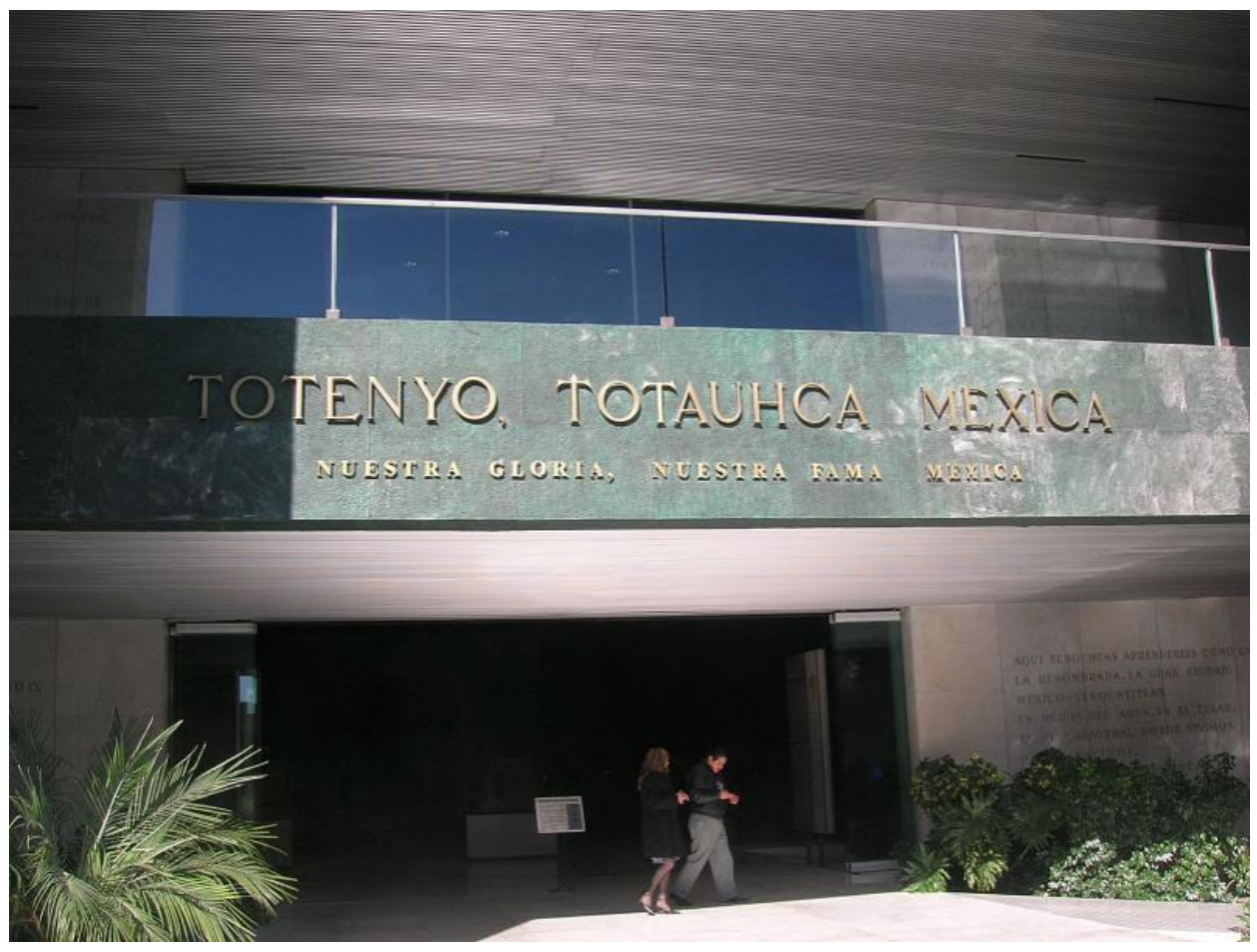

Figura 1. Friso de entrada a la Sala Mexica, Museo Nacional de Antropología de México. 
salas, lo que le otorga más monumentalidad y sacralidad. Sin embargo, hay que reconocer que el edificio de MNA, a diferencia de otros grandes museos nacionales latinoamericanos ${ }^{9}$, no cuenta con una arquitectura de los clásicos "museo-templo" de fines del siglo XIX, con grandes escalinatas y columnas de estilos arquitectónicos griegos por donde se accede al saber y donde reina "lo culto" (García Blanco 1999; Hernández Hernández 1998). Esto puede obedecer a dos cuestiones, en primer lugar, porque el origen de "lo mexicano" no se puede buscar en la "cuna de la civilización" (Grecia antigua), sino en las culturas mesoamericanas. Por otro lado, el nuevo edificio del MNA fue construido en la década del sesenta, cientos de años más tarde que los grandes museos clásicos, y con una clara intención de "democratizar" el conocimiento y educar al pueblo.

En la actualidad, el museo está organizado en seis subdirecciones, Arqueología, Etnografía, Museografía, Técnica, Administrativa y de Protección de Bienes Culturales. A su vez, algunas de ellas están divididas en departamentos. En la actualidad la Subdirección de Arqueología contiene aproximadamente 30.000 piezas enteras, las cuales fueron obtenidas principalmente por la recolección/compra de coleccionistas y el desarrollo de investigaciones arqueológicas. Las piezas arqueológicas están distribuidas en las salas de exhibición, en la bodega y en la bóveda, y en exposiciones temporales.

\section{Preservar: coleccionar y conservar}

En la red del sistema museológico existe una interrelación sin jerarquías entre las tres funciones básicas del museo, preservar, investigar y comunicar. En líneas generales se puede definir a la preservación como el mantenimiento del valor cultural del objeto (van Mensch 1990). Coleccionar es la función que origina y sustenta la existencia de un museo y le otorga permanencia; mediante esta práctica el museo conforma o incrementa la colección de forma continua (López Barbosa 2001). Coleccionar incluye la selección de objetos, su ordenamiento y clasificación según distintos principios, valores y significados de entender el mundo (Clifford 1993). Desde el punto de vista histórico, autores como Morales Moreno (1994) proponen que el MNA en una primera etapa, desde su fundación hasta 1867, se caracterizó por el coleccionismo de objetos. A partir de esa fecha, cuando el Museo pasa a tener carácter público, comienzan a realizarse los primeros catálogos de colecciones.

La riqueza de las poblaciones indígenas que habitaron el actual territorio mexicano permitió, y sigue permitiendo, la recolección legal e ilegal de toda clase de piezas. Antes de la legislación de $1972^{10}$, todas los objetos extraídos en investigaciones arqueológicas debían concentrarse

\footnotetext{
${ }^{9}$ Por ejemplo el Museo de Ciencias Naturales de La Plata, Argentina.

10 Ley Federal sobre Monumentos y Zonas Arqueológicas, Artísticas e Históricas.
}

en el MNA, con posterioridad se decidió descentralizar el acopio de piezas, quedando las mismas en los museos regionales (Martha Carmona Macías, Subdirección de Arqueología, com. pers. 25/03/2010). Esto interrumpió abruptamente el flujo de ingreso de las mismas al MNA, sin embargo, en la actualidad siguen ingresando algunas partidas de colecciones, aunque en menor medida, producto de particulares que ceden ${ }^{11}$ las mismas al Museo.

Sumada a la recolección de piezas se encuentra la documentación y su clasificación, que será la base para organizar la información y de esta manera darle sustento a las otras funciones del museo. El MNA cuenta con un archivo documental (Archivo Histórico del MNA) y en la actualidad se encuentran realizando tres grandes proyectos, la catalogación de la documentación de las tres últimas décadas del Museo, la digitalización de los catálogos anteriores y la evaluación del estado de conservación de los documentos que contiene.

La conservación se encuentra incluida dentro de las funciones de preservación de los museos, además de la recolección y documentación de piezas. Esta puede ser entendida como todas aquellas acciones tendientes a garantizar la permanencia de las características físicas originales de cada objeto y corresponde a los museos aplicar los medios necesarios para evitar o detener su deterioro y cuidarlas de una preservación o restauración inadecuadas. Se trata principalmente de una función técnica que se apoya en la investigación y se concentra tanto en las piezas, como en el edificio (López Barbosa 2001: 32). Así es como actualmente la conservación debería ser aplicada, tanto en los procesos expositivos, como en el almacenamiento y en los movimientos o traslados de colecciones y amerita trabajo interdisciplinario entre conservadores, curadores y museógrafos (Pearce 1990).

A nivel internacional, desde la década de 1950, pero con mayor peso entre los '60 y '70 se comienzan a realizar los primeros planteamientos teóricos en relación al control ambiental para la conservación de colecciones (Coremans 1969; Stolow 1987; Thomson 1998). Con estos estudios se empezó a reconocer la importancia del rol del conservador y de la conservación en el museo mediante la aplicación de métodos y técnicas científicas. En la actualidad, el conservador tiene varios ámbitos de incumbencia, entre las que se destacan, la realización de dictámenes del estado de conservación de los objetos y la medición, registro y control del medio ambiente en los sectores de exposición y almacenaje (temperatura, humedad relativa, iluminación, plagas, contaminación). En los sectores de almacenamiento forma parte de la

\footnotetext{
11 Las piezas arqueológicas son de dominio del Estado, sin embargo los particulares pueden tener en custodia piezas, siempre y cuando las registren en la Subdirección de Inventarios Nacionales (INAH) y pueden "devolverlas" al Estado, cediendo su tenencia al MNA.
} 
toma de decisiones del emplazamiento, tipos de soportes, materiales utilizados, forma de guardado y embalajes. Mientras que sus opiniones son valiosas para el montaje de exposiciones, la realización de soportes, la calidad de las vitrinas y la supervisión de las condiciones de conservación. En los traslados es importante el diseño de los embalajes y el control de las condiciones durante los movimientos y el transporte. En todos los casos, tiene injerencia en las cuestiones básicas de mantenimiento y limpieza de los objetos. Por último, en los planes de seguridad y prevención de siniestros (Cronyn 1990; Stanley Price 1995).

Desde 1966 México cuenta para la formación de profesionales de la conservación con la Escuela Nacional de Conservación, Restauración y Museografía "Manuel del Castillo Negrete". Sin embargo tuvieron que trascurrir casi treinta años para comenzar a valorar la conservación en el museo y reconocer que la misma está implicada en el almacenamiento, manejo y administración de las colecciones. Según algunos entrevistados (Sergio González García, Departamento de Restauración, com. pers., 23/02/2010) el principal problema radica en la incorporación tardía de los conservadores a los planteles de estas instituciones, ya establecidas y de larga trayectoria, generando alteraciones en los "usos y costumbres" de curadores y museógrafos, con el consecuente surgimiento de conflictos y rispideces. El conservador incursiona en los ámbitos de los museos, generando un fuerte impacto en la investigación y la museografía, y viene a cuestionar el estereotipo vigente del restaurador "como artesano capacitado en restaurar objetos individuales en el taller" (González García 2009: 13). En ese sentido es necesario destacar que la realización de un nuevo edificio en el Bosque de Chapultepec (en 1964) no contempló la conservación sino el almacenamiento de piezas y colecciones. En ese momento el interés estaba en las funciones pedagógicas y estéticas, lo cual implicó un diseño de salas con iluminación natural que accede por grandes ventanales y puertas, permanentemente abiertas (Ramírez Vázquez et al. 1968). Por su parte, el diseño de las vitrinas incluyó la utilización de vidrios de grandes dimensiones sin sellado. Ambos sistemas favorecen la entrada de polvo, rayos UV, contaminantes y las alteraciones de humedad del exterior que repercuten en las salas, las vitrinas y las colecciones (González García 2009). Tampoco el nuevo edificio del MNA contemplaba la construcción de un área de restauración. Pasaron varios años para que la misma se creara y luego de "deambular" por diversos sectores improvisados del museo fue instalada "temporariamente" en los jardines, lugar de su ubicación actual. La localización por fuera de las instalaciones principales del museo le brinda una serie de beneficios que los mismos conservadores resaltan, como por ejemplo, iluminación natural, ventilación y mayor seguridad en el manejo de sustancias peligrosas (Gilda Salgado Manzanares, Departamento de Restauración, com. pers., 03/02/2010).
En la actualidad, hay una especialidad dentro de la conservación que estudia y aplica aquellas acciones que evitan o reducen el potencial daño de las colecciones en su conjunto. De esta manera, la llamada conservación preventiva se concentra en el no-tratamiento, en el estudio, monitorio y control de los entornos ambientales y su acción sobre los distintos materiales (Cronyn 1990; Perdigón Castañeda 2004-2005). Los primeros antecedentes de esta clase de estudios se realizaron en el MNA a principios de la década de 1990 y consistieron en la evaluación de las condiciones ambientales del mismo (Moreno y Montes del Oca 1990-1991, citado en González García 2009). Sin embargo, en la reestructuración que se realizó a fines de esa época, estas propuestas no fueron consideradas, como tampoco fueron discutidos los diseños de vitrinas y los montajes con los conservadores. El criterio de la nueva reestructuración se basó principalmente, en ciertos aspectos de la museografía, como por ejemplo, en la iluminación dirigida y en la reorganización de la gran cantidad de piezas expuestas. A pesar de ello, en esos años el laboratorio de conservación del MNA logró que se confeccionaran vitrinas selladas para la exposición de textiles y plumario, con iluminación por fibra óptica y la utilización de gel de sílice para el control de la humedad relativa en las mismas (González García 2009).

Durante el año 2006 se realizó un nuevo monitoreo ambiental realizado por uno de los integrantes del Departamento de Restauración del MNA (González García 2009), tomando tres ejes de análisis, el ámbito de la sala, la vitrina normal y la vitrina sellada de la Sala del Preclásico. El diagnóstico de esta investigación reveló una serie de inconvenientes relacionados principalmente con el sistema de vitrinas (abiertas), el cual favorece el ingreso de polvo, de humedad, de insectos y hasta de basura introducida por los visitantes. Asimismo, algunas de las vitrinas contienen piezas de distintos materiales (orgánicos e inorgánicos), los cuales deberían estar separados, ya que requieren una serie de recaudos conservativos diferenciados (Figura 2). Otro de los factores de riesgo de las vitrinas es la vibración de los pisos que repercute en las piezas y en los vidrios. Por último, el investigador comenta otro inconveniente que está relacionado con el deterioro de los huesos humanos exhibidos en la reproducción de los entierros de la sala. Como se puede observar, las soluciones son básicamente técnicas, pero necesariamente implican una toma de decisión política (González García 2009: 137). Afortunadamente, desde la nueva gestión asumida en el año 2009, muchas de las propuestas realizadas como resultado de este estudio están siendo aplicadas.

Asimismo hay que mencionar la reestructuración y acondicionamiento de las bodegas de Arqueología y Etnografía que se está llevando adelante. En el caso de esta última, el proyecto en la actualidad está más avanzado, encontrándose en la última fase de 


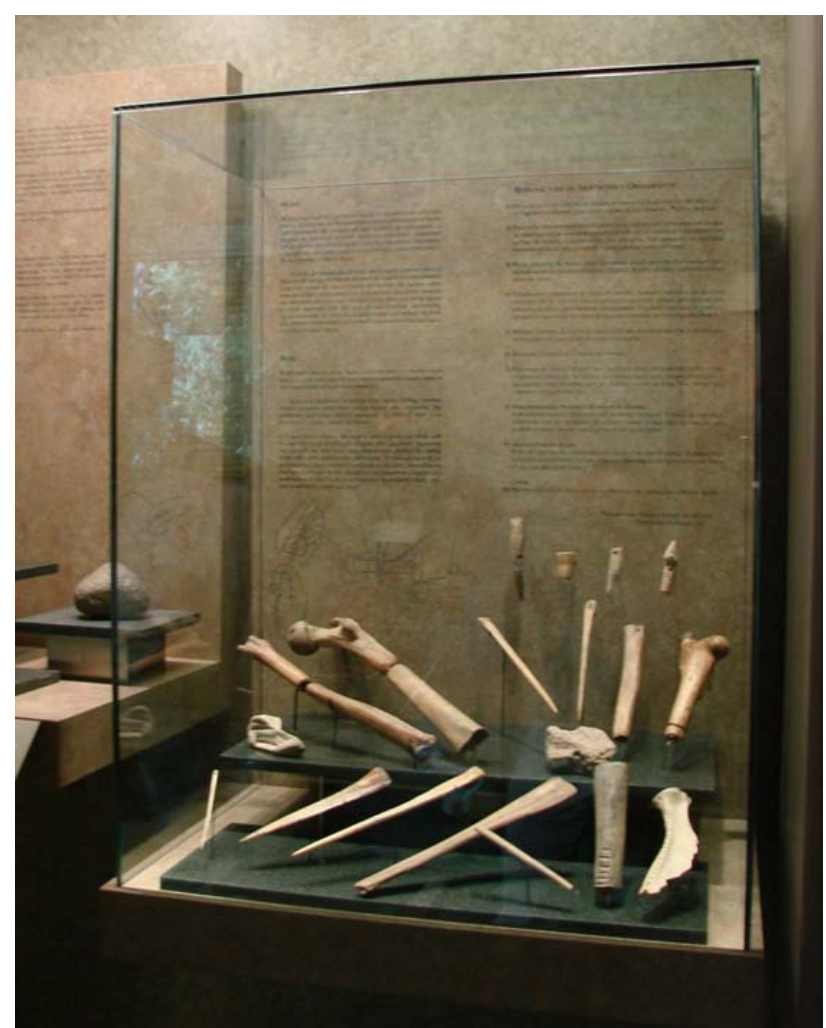

Figura 2. Reestructuración de una de las grandes vitrinas de la Sala Preclásico donde se incorporó un capelo de vidrio sellado para resguardo de material óseo. Además incluye gel de sílice para control de la humedad y un dispositivo de monitoreo de la misma.

disposición de las colecciones en los nuevos anaqueles y estantes, los cuales cumplen las normas de conservación recomendada. En el caso de la bodega de Arqueología, está en una primera etapa de reestructuración del edificio mismo y colocación de rieles para el amoblamiento.

Por último, es importante resaltar el trabajo que realiza la Subdirección de Protección de Bienes Culturales, que tiene a su cargo resguardar los bienes patrimoniales dentro del museo y garantizar la seguridad de los visitantes y de los trabajadores mediante el personal de seguridad. También se encarga del control de entrada de los visitantes, del monitoreo permanente por medio de 216 cámaras, del guardarropa y es responsable de la seguridad de los visitantes especiales (se reciben primeros mandatarios y personalidades de la cultura mundial). Desde este sector impulsan constantemente la formación del personal de seguridad en distintos aspectos que tienen que ver con el Museo, sus colecciones, la arqueología y etnografía, entre otras cuestiones. Reconocen que la mayoría de las veces los visitantes sólo establecen contacto con este personal del Museo, por lo tanto consideran que la cordialidad y el buen trato es crucial para llevar adelante esta tarea (Patricio Mejía, Subdirección de Protección de Bienes Culturales, com. Pers. 18/03/2010). Por otro lado, desde el punto de vista normativo cuentan con numerosas medidas de seguridad dictadas por el Estado. En la actualidad están ajustando algunas normas en conjunto con otros museos, y diseñando un Plan Integral sobre la Seguridad en los mismos. En ese mismo sentido, el MNA aplica el Programa de Prevención de Desastres en Materia de Patrimonio Cultural (PREVINAH) perteneciente al INAH, el cual maneja la prevención, atención y restablecimiento ante el riesgo de fenómenos antropogénicos (violencia, tráfico, robo, fanatismo religioso, turismo sin manejo) y catástrofes naturales, principalmente sísmicas.

\section{Investigar}

La investigación es otra de las funciones de los museos y se centra, básicamente en el estudio y la actualización constante del conocimiento acerca de las colecciones. Incluye además, la elaboración de guiones científicos y publicaciones académicas y la creación de archivos documentales. Esta función está en estrecha vinculación con las otras funciones del museo, ya que marcha en forma simultánea con la preservación, y a veces, la antecede. Asimismo, aporta el material esencial para la comunicación. En muchos casos, los museos se han vinculado con instituciones científicas y universitarias para retroalimentarse mutuamente (López Barbosa 2001).

Es interesante observar cómo en México, la ciencia antropológica cobra relevancia impulsada por el Estado y esto se debe a la preocupación acerca de la integración de las poblaciones indígenas a la nación. Desde mediados del siglo XIX, hay un impulso para que las distintas disciplinas antropológicas aborden dos grandes problemáticas, los "indios muertos" (la arqueología y en cierta forma, la historia), y los "indios vivos" (la etnología, etnografía, el folklore) (Gallegos Téllez Rojo 2008:79). Esto se ve reflejado durante el Porfiriato (1876-1911), donde el Museo Nacional comienza a ser el centro de publicaciones y reuniones científicas nacionales e internacionales y desde el 1906, ofrece una variedad de cursos de estas disciplinas. En ellos se incluía la realización de prácticas de laboratorio y de campo, principalmente en etnología y arqueología. Los estudiantes concluían cada curso con un ensayo el cual era publicado en los Anales del Museo Nacional. Asimismo se había generado una vinculación con la Escuela Internacional de Arqueología y Etnología Americana, lo que permitió introducir técnicas de excavación y de estratigrafía a las prácticas de campo arqueológicas. Claramente se observa como el Estado se ocupó y destinó recursos para la formación de un ámbito de estudio y discusión (en el Museo) de la población indígena con el propósito de su integración a una nación (Gallegos Téllez Rojo 2008). Sin embargo estos grupos nativos, en cierta forma, eran considerados un problema para la modernización, principalmente por la gran diversidad de lenguas, mientras que los restos arqueológicos eran los testimonios de un pasado rico y del cual estar orgullosos (Nalda 1998). Con la revolución, este espacio ganado por los cursos de formación se abandonó y en 1914 ya no existiría, se cerraron los departamentos 
y cesaron las publicaciones. Esto estuvo vinculado a que la mayoría de los profesores estaban relacionados con el porfirismo, lo que implicó persecuciones y exilios. Sin embargo, en los años post-revolucionarios (1911-1925), Pruneda y Galindo y Villa, generaron una nueva conceptualización del museo ligado a la ciencia y la docencia. Sus influencias pedagógicas consistían en la "observación-contemplación" de piezas, a través del cual se podían transmitir conocimientos y alcanzar la educación popular. Paralelamente, se proponía la presentación del pasado mediante la clasificación en "culturas" que revela la influencia del Particularismo Histórico boasiano (Trigger 1992), vigente en EE.UU para esa época. A pesar de estas diferencias con el período anterior, subyacen dos ideas primordiales que persisten, en primer lugar, que la ciencia es una verdad indiscutible por medio de la cual se llega a un conocimiento objetivo, y en segundo lugar, que a través de ella se alcanzará el progreso (Morales Moreno 1994). Para la misma época otros dos investigadores dejaron una marca importante en la antropología mexicana. Manuel Gamio fue un joven antropólogo que propuso que el museo debía poseer un fin de justicia social, ya que la arqueología y la antropología eran los medios para que las poblaciones se superen. Por otro lado, Alfonso Caso, fue el promotor de las disciplinas, fundando en 1939 el Instituto Nacional de Antropología e Historia (INAH) y la Escuela Nacional de Antropología e Historia $(E N A H)^{12}$, dependiente del mismo. Bajo el ámbito del INAH se habilitaron grandes zonas arqueológicas privilegiando las excavaciones y reconstrucciones de monumentos.

Con respecto a la funciones concretas de los investigadores del MNA, en la actualidad, cada sala está a cargo de curadores especializados en el tema (siete en total) y sus obligaciones son: la investigación de las colecciones (bodega, bóveda y sala), actualización de cedularios ${ }^{13}$ en sala y cambios de piezas, elaboración de guiones y selecciones de materiales para exposiciones, inventarios frecuentes y participación en proyectos de investigación en su área de trabajo. Sin embargo, hay que destacar que en la práctica, los curadores no se dedican a realizar actividades de investigación propiamente dichas, sino más bien actualizaciones de contenidos de la exposición permanente, los cuales fueron reformulados hace más de 12 años. En el caso de la Subdirección de Etnografía, el trabajo de los investigadores es más activo en la generación de nuevos guiones. Esto se debe a que esta área, históricamente, fue considerada de menor relevancia que la arqueológica, dentro del museo. Por ello, se han impuesto, al interior de la subdirección, impulsar continuamente la realización de guiones curatoriales nuevos con el propósito que sean evaluados y potencialmente materializados (Leopoldo Trejo Barrientos y Eugenia Sánchez, Subdirección de Etnografía, com.

\footnotetext{
12 Única institución pública donde se forman arqueólogos.

13 Término que en México se suele emplear para los distintos tipos de cartelerías (paneles, etiquetas o cartelas).
}

pers, 04/03/2010).

Dentro de las funciones que cumplen los investigadores en el MNA están las relacionadas a las exposiciones temporales, las cuales son principalmente arqueológicas. El museo en la actualidad posee 17 exposiciones de estas características (780 piezas en total), que se encuentran distribuidas por numerosos países europeos, norteamericanos y en menor medida, asiáticos. La mayoría de los guiones de estas exposiciones no son realizados por los curadores del MNA, hecho que en otros años no ocurría ${ }^{14}$. Actualmente los guiones llegan elaborados por las instituciones extranjeras que solicitan las piezas en préstamo y los curadores actúan solo como comisionados en el montaje y desmontaje de las mismas y sus traslados. Sin embargo los investigadores insumen gran parte de su tiempo en estos viajes debido a la duración e importancia que poseen estas exposiciones en el extranjero.

En este apartado hay que mencionar el trabajo del Departamento de Movimientos de Colecciones Arqueológicas (DMCA). El mismo es el encargado de los preparativos del préstamo para las exposiciones temporales, luego del estudio de las condiciones de seguridad y del guión por parte de la Dirección del MNA y de la CNMyE. Paralelamente ,la institución solicitante debe aprobar el presupuesto del traslado y montaje (seguros, gastos de embalaje, traslado de colecciones y de personal, mano de obra, etc.). Dentro de las funciones del DMCA se encuentran: el acopio de obra que incluye los dictámenes de conservación y fotografías; la confección de los catálogos de obra de viaje mediante la elaboración de una ficha técnica de cada pieza ${ }^{15}$ y la relación de embalaje, la cual consiste en la descripción de los pesos de las piezas, de los soportes y contenedores y sus disposiciones en las cajas generales de viaje. Por último, se encarga de los órdenes de salida y el seguimiento de las colecciones durante los traslados a otros museos o aeropuertos.

Para finalizar el análisis de la funciones relacionadas a la investigación es necesario mencionar algunos supuestos teóricos disciplinares que subyacen en los discursos expositivos de las salas de Arqueología, haciendo la aclaración que este aspecto ameritaría un estudio de mayor profundidad. Solamente a manera de ejemplo una cuestión que llama la atención es la división de las salas en "culturas", además en ellas se pueden encontrar etiquetas que explican las "tareas de las mujeres o las de los hombres" o los "modos de producción". Por lo menos

\footnotetext{
14 La excepción la constituyen una serie de exposiciones temporales, tales como "El imperio azteca", "Isis y la Serpiente emplumada", o "Teotihuacan, ciudad de los dioses", las cuales fueron elaboradas por el arqueólogo Felipe Solís Olguín (director de la Subdirección Arqueología) destinadas a prestigiosos museos como, el Guggenheim de Nueva York o el de Bilbao (entre los años 2004-2005) (Velasco Alonso 2009).

15 En algunos casos deben investigar y actualizar esa información y el DMCA recurre a los curadores.
} 
en Sudamérica, hace algunos años que la arqueología está discutiendo el uso de la categoría "cultura", la problematización acerca de cuestiones de género y los grandes sistemas clasificatorios de las sociedades jerárquicas (Gnecco y Langebaek 2006; Nielsen 2006; Williams y Alberti 2006; Williams et al. 2007; entre otros). Muchos museos, principalmente los universitarios, ya han dado cuenta de ello. A su vez, estas instituciones cada vez más emplean discursos multivocales, o por lo menos, reconocen explícitamente la diversidad de narrativas que pueden existir acerca del pasado (Museo Antropológico de Córdoba, Argentina; el Museo Universitario de Antropología de Antioquia o el Museo del Oro, ambos en Colombia). Sin embargo, según se desprende de las entrevistas y las observaciones realizadas a los investigadores (incluido directivos) del MNA, ninguna de estas cuestiones fue manifestada ni problematizada ${ }^{16}$.

\section{Comunicar y exhibir}

Puede entenderse la comunicación de los museos como la interpretación y la exhibición de las colecciones. Se trata de la proyección a la sociedad del conocimiento generado por la investigación y la conservación porque de ellas depende para su accionar (Hernández Hernández 1998). Una exhibición necesita una narración coherente entre las piezas y las ideas, y un diseño espacial, gráfico y lumínico que despierte los sentidos; de esta manera le ofrecerá al público la posibilidad de educación y deleite. Pero comunicar no solamente implica exhibir, sino también la realización de publicaciones de divulgación, catálogos, videos y visitas guiadas (López Barbosa 2001).

Para discutir la forma de exhibir en el MNA históricamente, es necesario analizar la museografía a través del tiempo. Esto trae aparejado también, la discusión acerca del mensaje narrativo de las exposiciones (García Blanco 1999). Las primeras reflexiones acerca de la manera de exhibir fueron realizadas en la segunda década del siglo XX, para esa época ya se explicitaban los supuestos positivistas que subyacían a la misma: "en los museos de México, el pueblo adquiere conocimientos amplios, por medios objetivos, por exposición técnica y por comparación lógica" (Montes de Oca 1923, citado en Morales Moreno 2007:45). Con posterioridad, en la década de 1960, la museografía se orientó fundamentalmente al aspecto estético y educativo y el nuevo edificio del MNA en Chapultepec sería un representante de estas nuevas corrientes, pero seguía manteniendo los mismos principios originales antes explicitados. Para ese entonces se comenzaron a realizar exposiciones temporales con nuevas formas de exhibir piezas, por ejemplo, por fuera de las vitrinas o usar

\footnotetext{
16 Otros museos han retirado de exhibición los restos humanos en función de recomendaciones profesionales éticas y de reclamos indígenas actuales (Museo Etnográfico Juan B. Ambrosetti y el Museo de Ciencias Naturales de La Plata, Argentina). Esto no ocurre en el MNA ni es considerado como problema.
}

colores violentos e iluminaciones dirigidas con el fin de provocar sensaciones (Vázquez Olvera 2005). Sin embargo, no es hasta fines de la década de 1970 y 1980 , que la museografía nacionalista mexicana recibió una fuerte crítica, proveniente desde las ciencias sociales. Así es como el antropólogo García Canclini señaló que nada había cambiado. Tanto en los estudios de visitantes del MNA de 1952, como los de treinta años más tarde, indicaban que el museo era primordialmente visual y monumental (García Canclini 1990:176). Pero la mayor crítica estuvo dirigida al mensaje del MNA (Bonfil Batalla 1987, García Canclini 1990) más que a la manera de exponerlo. Este revisionismo se encuadraba en una nueva discusión acerca del rol de México en la globalización mediática y el multiculturalismo postmoderno, lo cual condujo a repensar la importancia de los museos en los imaginarios nacionalistas (Morales Moreno 2007).

Según estos estudios, el MNA obviaba mencionar los procesos y conflictos históricos que atravesaron los indígenas, y por los cuales fueron diezmados (García Canclini 1990). Las narrativas que brindaba el museo construían una representación del "indio petrificado", reproduciendo prácticas hegemónicas (Morales Moreno 2004). A esto se le sumaba la falta de continuidad entre las salas de Arqueología y las de Etnografía, debido principalmente a la distribución de las mismas, ya que las primeras se encontraban en la planta baja y las segundas, en el primer piso. En la actualidad esto continúa así, a pesar de que cada sala arqueológica tiene su contraparte en las salas superiores de Etnografía (por ejemplo, a la Sala Maya arqueológica le corresponde la Sala Maya actual en el primer piso), sigue generando una sensación de que las agrupaciones indígenas, con sus problemas de tenencia de tierras, pobreza y analfabetismo, no tienen vinculación con los indígenas gloriosos y tallados en la piedra, representados en las Salas de Arqueología. Igualmente hay que hacer una aclaración, no todo el pasado es motivo del mismo orgullo nacional, en cierta forma, solo el mexica ${ }^{17}$ es representativo de "lo mexicano" (Morales Moreno 2007; Pérez Montfort 2001). Es el esplendor del imperio azteca el que causó gran impacto a los españoles de Cortés y sus ruinas en la actualidad son evidencias de su grandeza y poderío, mientras que el resto de las poblaciones vecinas (muchas de ellas tributarias de los mexicas) no adquirieron el mismo prestigio ni orgullo.

Ramírez Vázquez (2008) en el "Proyecto de Reestructuración de las Salas de Exhibición de Arqueología y Etnografía" del MNA (1998-2004) señala que el visitante dispondrá de salas renovadas de alto impacto estético y pedagógico. Esto se materializó mediante la instalación de réplicas de murales arqueológicos, palacios y tumbas, o la utilización de videos ${ }^{18}$, con el propósito de permitir la

\footnotetext{
${ }^{17} \mathrm{Y}$ en menor medida, el maya y el teotihuacano. Este último se trata de una ocupación anterior a los aztecas, en los mismos alrededores del valle de México.

${ }^{18}$ Algunas turistas italianas han mencionado que el museo cuenta con
} 


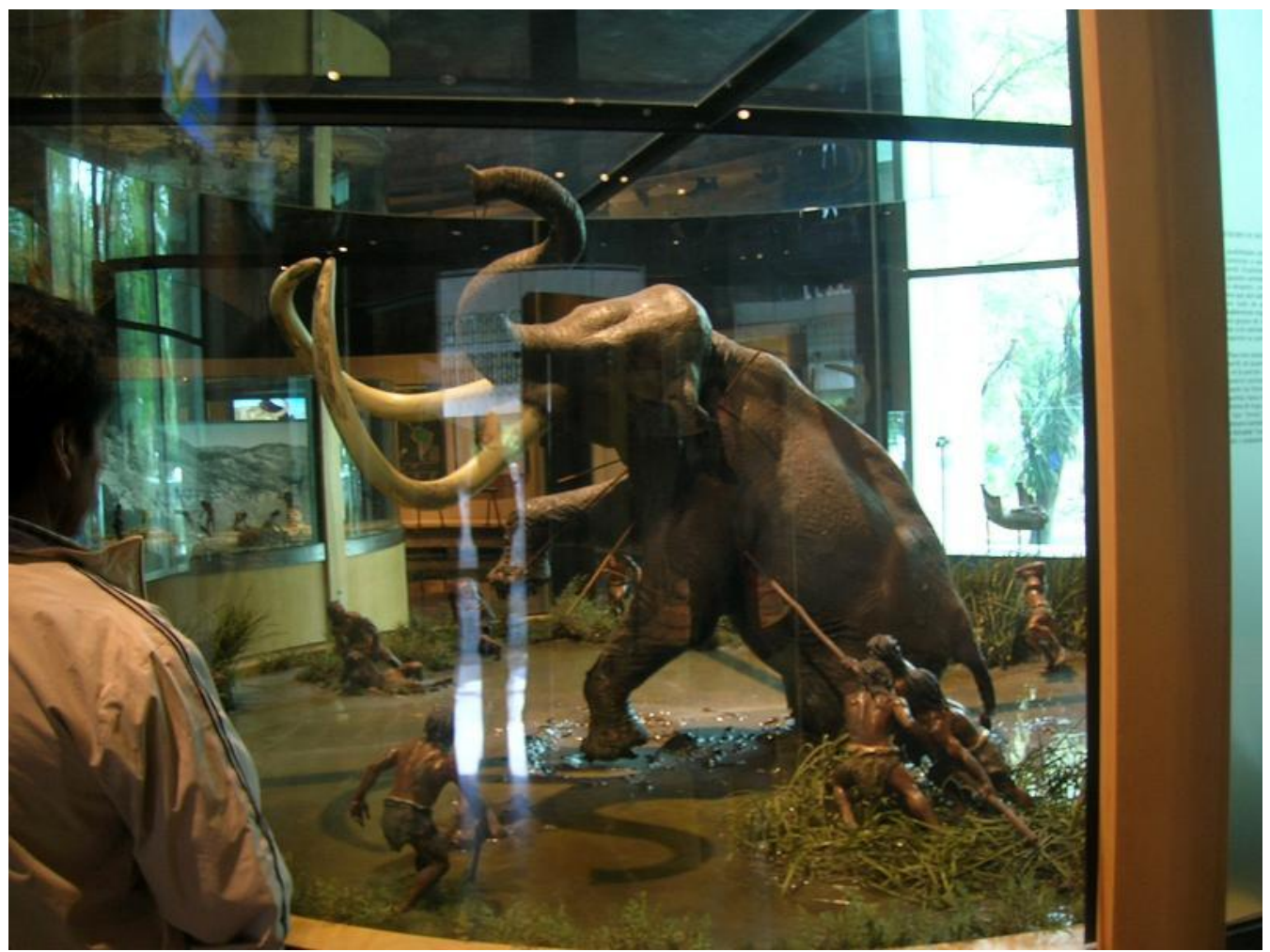

Figura 3. Maqueta que representa la caza de un mamut en la Sala de Poblamiento de América.

contextualización y la mayor comprensión de la cultura material de estas sociedades. En el caso de las salas "Introducción a la Antropología" y "Poblamiento de América" hubo un mayor esfuerzo en la ambientación y el empleo de infografías y maquetas debido, quizás, a que son las dos salas con "menor cantidad" de objetos arqueológicos expuestos, aunque las de mayor puesta museográfica de todo la sección de Arqueología ${ }^{19}$. (Figura 3)

Es decir que, la reestructuración se basó principalmente en sensaciones visuales, a pesar que el ordenamiento responde a asociaciones espaciales (por regiones), temporales (desde lo más antiguo), y culturales (por ejemplo, procesos productivos). Sin embargo, en algunas salas, estas claves asociativas (sensu García Blanco 1999) a veces se pierden. Por ejemplo, en el salón principal de la Sala Mexica la cartelería es escasa y la sola presencia de una gran cantidad de objetos monumentales magníficos generan contemplación, más que comprensión, es decir que, sin leer se puede apreciar la grandiosidad del pasado. Por otro lado, García Canclini (1990) ya planteaba para principios de la década de 1990, que el mensaje de las salas de Arqueología era unidireccional, sin lugar para

numerosas pantallas, aunque en algunas de ellas "no proyectaban la información que les correspondía, el video era lento, aburrido y sólo en español" (entrevista realizada por Fernando Gómez Castellanos, 4/03/2010).

19 Una niña que acompaña a una visitante de procedencia local señala que, lo que más le agradó del museo fueron las maquetas de la sala de Poblamiento de América, en especial la que representa la caza de un mamut (entrevista realizada por Fernando Gómez Castellanos, 4/03/2010). la interacción con el visitante y donde se transformaba en un mero espectador. Posteriormente se incorporaron algunos elementos que permitían cierta interactividad con el público (algunas pantallas) pero las mismas tuvieron poca vida útil y desde ese momento, no se repusieron (Rafael Balverde, Subdirección de Museografía, com. pers. 22/02/2010).

La reestructuración de 2004 no afectó al guión científico de las salas de Arqueología, ya que se continúa presentando principalmente a "lo mexica" como la identidad colectiva de México ${ }^{20}$, pero reservado a un pasado estático y contemplativo. Según Ramírez Vázquez (2008), el espacio de exhibición renueva el compromiso de los mexicanos con sus ancestros y sus hermanos indígenas como habitantes de la nación. En cambio, en las salas de Etnografía se observa el tratamiento de temas actuales introduciendo cuestiones como los movimientos indigenistas, el impacto de las nuevas religiones, la migración y la occidentalización de los modos de vida. En ese sentido, la etnóloga María Eugenia Sánchez menciona sus constantes viajes a las comunidades para ponerse al día y promover la modificación de la información antropológica y la creación de nuevos exposiciones temporales (Eugenia

\footnotetext{
20 Isabel Salinas de la Ciudad México, resalta el gran orgullo que representa para ella ser mexicana y poder visitar un museo en el que se encuentren "las raíces de su pueblo y de ella misma", sin embargo hace mención que por formación escolar la sala que más le gustó fue la Mexica, pero por gusto personal elegiría la de Introducción a la Antropología (entrevista realizada por Fernando Gómez Castellanos, 4/03/2010).
} 
Sánchez, Subdirección de Etnografía, entrevista realizada por Fernando Gómez Castellanos, 08/03/2010).

Ahora bien ¿cómo comunica su mensaje el MNA, más allá de la exhibición? En este punto es necesario resaltar el trabajo que realizan dos departamentos que dependen de la Subdirección Técnica. En primer lugar, el Departamento de Servicios Educativos que tiene bajo su responsabilidad la atención al público preescolar, primario y secundario. En segundo lugar, el Departamento de Promoción Cultural que es el encargado de recibir mediante visitas guiadas a bachilleres, universitarios, personas distinguidas y público en general. El Departamento de Servicios Educativos (DSE) fue creado en 1949, incorporando 37 profesores orientadores (AHMNA, vol. 17083, 1962:160), en 1964 el número ascendió a 60, siendo los objetivos del área "ser un centro de servicio para la comunidad, fomentando el amor, respeto y exaltación a la Patria" por medio de visitas guiadas. Otro objetivo es "lograr que el conocimiento de la historia de México sea claro, objetivo y apegado a la verdad, de modo que el alumno pueda comprender su presente y explicarse la proyección futura $y$, de esta manera, tender un puente entre el museo y la comunidad". Para aquellos tiempos las encuestas a los alumnos indicaban que el museo les permitía fácilmente aprender la historia, mientras que los maestros consideraban al museo y a las visitas guiadas como auxiliares insustituibles de la escuela (AHMNA, vol. 17083, 1962:162). En ese sentido, hay que resaltar como los museos ya se habían plegado a los programas oficiales del Ministerio de Instrucción Pública y que lo continúan haciendo hasta el presente ${ }^{21}$.

En la actualidad, el MNA sigue siendo considerado un instrumento auxiliar de la enseñanza y debe ser visitado obligatoriamente durante la etapa escolar de todo niño o niña. Aunque la cantidad de personal se ha visto reducido considerablemente, a tan sólo siete asesoras pedagógicas, el espíritu no ha cambiado. Según la jefa del departamento, los principales objetivos hoy son, reforzar el nacionalismo y mostrarles a los mexicanos y al mundo "quiénes somos" (Lourdes Garduño, Departamento de Servicios Educativos, com. pers., 10/02/201022. Según algunos visitantes mexicanos, "la visita al MNA es indispensable para tener presente, o recordar los conocimientos aprendidos en la vida escolar, y que con el paso del tiempo han sido olvidados en una u otra proporción" (R. Ascencio, señora mexicana, entrevista realizada por F. Gómez Castellanos, 04/03/2010).

\footnotetext{
21 Según la Jefa de Servicios Educativos, está a la espera de los nuevos libros de texto que distribuirá el Ministerio, para poder evaluar de qué manera se adaptará al discurso de los mismos (Lourdes Garduño, Departamento de Servicios Educativos, com. pers., 10/02/2010).

22 De esta manera, se puede entender la cantidad de visitantes que recibe el Museo, en el año 2009 la cantidad de escolares alcanzaron a los 24.955 niños. Igualmente el año 2009 fue atípico ya que recibió 15.000 estudiantes menos que en años anteriores debido a la epidemia de la Influenza A (Lourdes Garduño, Departamento de Servicios Educativos, com. pers., 10/02/2010).
}

Las visitas al MNA solicitadas por las escuelas incluyen la guía de 45 minutos en la sala requerida, un taller, donde en la mayoría de los casos, se decora o pinta una réplica de alguna pieza que observaron en sala y la presentación de un video institucional. El DSE además es el encargado de la confección de libros y cartillas para niños y docentes y organiza talleres para docentes y para otros niños, fuera del ámbito escolar y en época vacacional.

Por su parte, el Departamento de Promoción Cultural es el que se hace cargo del resto de los visitantes, mediante 12 guías en distintos idiomas. También coordina la agenda de eventos especiales que se realizan en el Auditorio (espectáculos, congresos, etc.) y distintas exposiciones temporales organizadas por la CNMyE. En el caso de las visitas, la mayoría de los guías tienen una vasta experiencia y toman continuamente actualizaciones, organizadas por el INAH. En ese sentido, es interesante resaltar que durante la observación de una visita, el guía introdujo una visión más problematizadora del mensaje que instala el guión de la sala. En ese caso, el discurso objetivo y veraz de la ciencia fue puesto en duda, y se mencionaron diversas facetas interpretativas de un mismo "hecho" (visita observada el 22/03/2010).

Por último, hay que señalar la importancia que el MNA le otorga a las opiniones de los visitantes recibidas mediante un buzón de sugerencias instalado en los accesos. De este tema se encarga la Subdirección Administrativa, la cual recolecta los formularios dejados por el público todos los días lunes. Se lleva un registro de cada una de ellas y se les responde a aquellos que han dejado sus datos. Las sugerencias y quejas son de toda clase, desde cuestiones relativas a las visitas guiadas, falta de información específica, problemas en las cédulas, información acerca de los horarios de acceso, hasta el acercamiento de información actualizada o alternativa ${ }^{23}$ en determinados temas tratados. Durante la estancia, se pudo conocer el arreglo de una cédula y la carta de agradecimiento remitida por el Museo debido a una sugerencia recibida. Otro caso fue la redacción de una carta de disculpas enviada a un visitante que no encontró a los sanitarios en condiciones, informándole que se habían tomado los recaudos para su solución.

\section{Balance entre las funciones}

Luego de haber desarrollado una recopilación histórica y una descripción de las tareas que se realizaron y realizan en el MNA, se presenta un breve análisis de las mismas con el fin de evaluar las funciones esenciales de este museo. En ese sentido, hay que aclarar que este trabajo no tiene pretensiones de efectuar una revisión exhaustiva del tema

\footnotetext{
23 Una de las cartas dejadas en el buzón era la fundamentación de por qué el MNA debía considerar la explicación de la existencia de extraterrestes en el desarrollo de las sociedades precolombinas (Juan Martínez Martínez, Subdirección Administrativa, com. pers. 22/03/2010).
} 
sino que más bien, se trata de una aproximación al estado de situación que presenta un museo antropológico de la trayectoria del MNA y en un contexto latinoamericano. Realizar un diagnóstico institucional exhaustivo del MNA requiere de un programa de investigación concreto y amplio, de tiempos más extensos y de mayores recursos humanos y económicos.

Las tres funciones de un museo, preservar, investigar y comunicar se encuentran interrelacionadas y un diagnóstico positivo de las mismas debería ser el resultado de un balance equilibrado entre las partes. Según lo desarrollado en este trabajo, se pueden rescatar varias cuestiones que han cambiado en la actualidad, en relación a la preservación en el MNA. En ese sentido, en la última década, el Museo ha implementado varios programas de conservación preventiva de colecciones en bodegas y vitrinas para las secciones de Arqueología y Etnografía. Asimismo, le ha otorgado la relevancia que requiere el Departamento de Restauración, tanto en su grado de autonomía hacia dentro del organigrama del museo ${ }^{24}$, como en la designación de un espacio único y específico con las condiciones necesarias para llevar adelante sus tareas. Además, el MNA posee un control ajustadísimo por medio de protocolos de los movimientos de las colecciones, en operaciones de embalajes y traslados internos o externos, y en los préstamos para la realización de exposiciones temporales. En ese sentido cabe mencionar que durante la última exposición mexicana, trasladada y montada en el Museo Quai Branly, el equipo comisionado por el MNA fue evaluado con la máxima puntuación que otorga la institución francesa (Martha Carmona Macías, Subdirección de Arqueología, com. pers., 22/03/2010). Por último, otro aspecto importante es la implementación de un programa de conservación de los documentos del archivo del Museo. Sin embargo, el mayor inconveniente se encuentra en romper los hábitos históricos que el personal posee y que se trata, principalmente, de la falta de reconocimiento de la importancia de la preservación de las colecciones. Para solucionarlo se requiere de fuertes decisiones políticas y una capacitación para todo el personal del Museo a fin de que conozca su relevancia.

A la hora de evaluar la esfera de la investigación se han relevado diversos proyectos en marcha pertenecientes a las áreas de Restauración, Etnografía, Servicios Educativos y Arqueología. En esta última Subdirección es donde los mismos investigadores mencionaron inconvenientes relacionados a la superposición de tareas que cumplen. Cada uno de ellos poseen a su cargo una de las salas permanentes y su trabajo se basa casi exclusivamente, en la actualización de la información que brinda la misma (nuevos fechados o nuevos descubrimientos). También tienen a su cargo la realización de inventarios y participan, como comisionados de las exposiciones temporales, las

\footnotetext{
24 El Departamento de Restauración históricamente dependió de la Subdirección Arqueología.
}

cuales requieren, en algunos casos, varias semanas y hasta meses en el exterior, realizando supervisiones e informes. Ellos consideran que la tarea administrativa y burocrática no les permite llevar adelante trabajos de investigación propios. Otra de las obligaciones en investigación es la elaboración de nuevos guiones científicos para las exposiciones permanentes y temporales, tareas que en Arqueología por lo general, no ocurren (a diferencia de Etnografía). Por un lado, porque la gran mayoría de las exposiciones temporales están diseñadas en el exterior y traen sus guiones ya confeccionados. Por otro lado, en el MNA el guión de la exposición permanente de Arqueología tuvo una renovación hace aproximadamente diez años por lo que no hay una propuesta de cambio a corto plazo, a pesar que el mismo evidencia cierta desactualización en algunas concepciones teóricas, antes mencionadas, las cuales ameritarían realizar reformulaciones.

En relación a las otras dos funciones, la comunicación en el Museo tiene una mayor trayectoria y varios aspectos a destacar en relación a algunas cuestiones museográficas y a los contenidos, no sólo de las exposiciones, sino también de las visitas guiadas y los talleres educativos. Con relación al análisis del espacio museográfico se pueden señalar una serie de aspectos que fueron identificados en el estudio de público realizado en el año 2000 por la CNMyE (Montemayor 2000). En primer lugar, la iluminación natural y la dirigida del MNA, en combinación con los colores de las salas, transforma estos espacios en lugares amigables y acogedores, a pesar de ello, la mayoría de los visitantes ${ }^{25}$ pasan menos de 20 minutos en cada sala, bajo el pretexto de que las mismas son monótonas ${ }^{26}$. En ese sentido la museografía es mencionada en tercer lugar en el ranking de las valoraciones positivas (81\%) del público (Montemayor 2000). Con respecto al largo del recorrido, la mayoría de los visitantes considera que el museo es demasiado grande e inabarcable, por lo que solo recorren dos salas, y otros alcanzan a recorrer cinco, como una excepción. Dentro de las otras valoraciones negativas mencionadas por el público (19\%), aparte de las dimensiones del museo, se encuentra en primer lugar, la cartelería y el cedulario, ya sea por su ausencia o porque hay demasiada información o, porque se encuentran en mal estado. El análisis del estudio de público mencionado (Montemayor 2000) indica que el principal motivo de satisfacción de los visitantes son las colecciones en sí mismas, que se aprecian principalmente desde lo visual, un aspecto que históricamente fue así (García Canclini 1990) y que, diez años después, también se resalta ${ }^{27}$. Otro

\footnotetext{
25 Este trabajo se realizó sobre la base de 768 encuestas (Montemayor 2000; estudio realizado dentro del Programa Nacional de Estudios de Público y facilitado por la Directora Técnica del archivo de la Coordinación Nacional de Museos y Exposiciones, INAH).

26 Esto ocurre en la mayoría de los museos (Pérez Santos 2000).

27 Por ejemplo, un turista italiano quedó impactado por las piezas interesantes que ha conocido (entrevista tomada por Fernando Gómez Castellanos, 04/03/2010).
} 


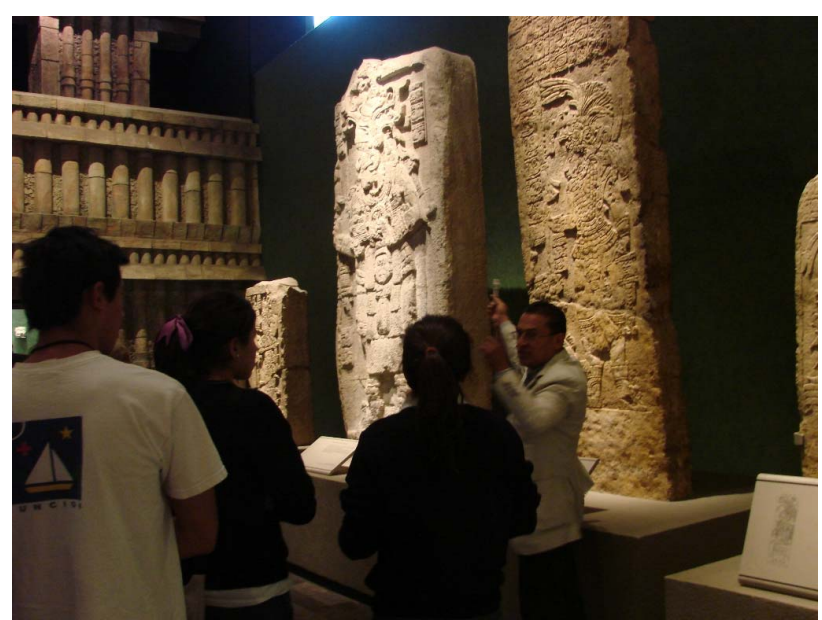

Figura 4. Visita guiada a público en general en la Sala Maya.

aspecto que se observa es que en la gran mayoría de las salas se apela a los recursos que se aprecian visualmente, como es el caso de escenografías, maquetas, réplicas y murales. Mientras que las que incluyen otras clases de percepción son sólo algunas réplicas de tumbas que permiten el acceso y recorrido y unos pocos videos, donde además de la imagen, el sonido es importante (Figuras 4 y 5 ).

Ahora bien, ¿cuál es la clase de conocimiento que el Museo propone? Se trata de un conocimiento objetivo, el de la ciencia, que se transmite mediante la distribución de las piezas y de su cedulario, otorgando una visión única, clara y convincente. El conocimiento es elaborado por los expertos y el Museo no brinda la posibilidad de incluir otras miradas. Ese conocimiento es construido con apoyatura de textos aunque los mismos no suelen ser apreciados por los visitantes. Los estudios indican que el tiempo real que la mayoría del público emplea en cada sala es de menos de 20 minutos, lo que no les permite leer la cantidad de información de las principales cédulas. La excepción es el 28\% de los estudiantes de Preparatoria $(n=353)$, es decir, los que leen con mayor profundidad la información, porque la requieren para sus tareas escolares (Montemayor 2000). Otro aspecto que hubiese sido interesante conocer es el grado de comprensión de los temas tratados en cada sala, lamentablemente este es un aspecto que no fue considerado a la hora de realizar el último estudio de público en el Museo. En suma, a partir de todo esto se desprende que, el Museo aspira a presentar un significado objetivo y único de las colecciones, generado por los expertos. Que la experiencia museística se reduce a lo visual o a lo textual y que el público es un mero espectador, al igual que en la década de 1980 (García Canclini 1990). En ese sentido, lo que aporta el museo es un servicio complementario a la educación formal, es decir, no es considerado como otra forma de aprendizaje diferente (Rico Mansard 2004).

Paralelamente, si se analizan los talleres y visitas guiadas para el público escolar, se observa una reproducción de

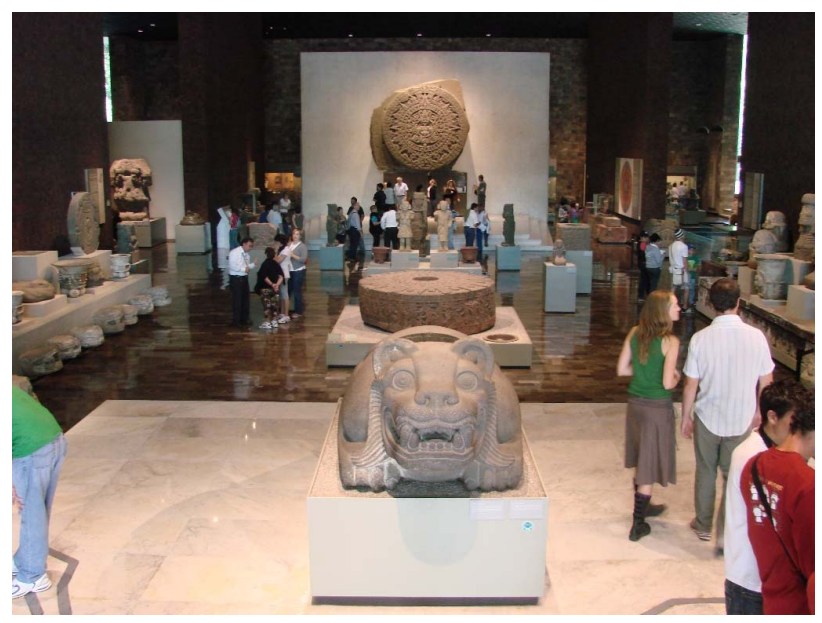

Figura 5. Sector principal de la Sala Mexica.

las formas establecidas por el museo. De esta manera, en el caso de los talleres, sólo buscan decorar réplicas de piezas arqueológicas, reproduciendo la primacía del objeto. En el caso de las visitas, hacen más accesible la información del cedulario, pero no aportan otras formas de experiencias. En ese mismo sentido se orientan las visitas guiadas al público en general, aunque en estas se crean algunos espacios para la duda en relación al discurso presentado por la ciencia. Por lo tanto, en líneas generales se puede decir que la comunicación y educación del MNA están dentro de las corrientes más tradicionales de la museología.

A manera de conclusión, este trabajo tuvo como objetivo presentar y discutir las distintas funciones atribuidas a los museos, preservar, investigar y comunicar, mediante una serie de métodos cualitativos de análisis (entrevistas, observaciones) de las prácticas actuales en el MNA. De este estudio se desprende que el Museo lleva adelante las funciones en diferentes intensidades y que algunas, como la conservación, implicó la creación de un espacio propio en los últimos años. Sin embargo, es importante mencionar que los museos son instituciones que se conformaron bajo otros parámetros, que no son los propuestos desde 1974 por el Consejo Internacional de Museos, por ello hay que evaluarlos desde su trayectoria histórica. En el caso del MNA de México el peso fundacional que tuvo la relación Estado-Arqueología-Museo lo ha marcado y lo mantiene explícitamente. Las renovaciones que ha sufrido a lo largo de su extensa trayectoria no apuntaron a revertir el símbolo de la grandeza mexicana que el Museo ostenta, así como ser instrumento fundamental en la educación del pueblo y en la consolidación de un único discurso respecto del pasado.

Olavarría, 29 de junio de 2010.

\section{Agradecimientos}

Las observaciones de campo y la información recolectada del MNA sobre las que se basa este trabajo fueron realizadas durante una estadía breve de investigación, en 
el marco de la beca Postdoctoral de la autora, financiada por el CONICET. La misma se llevó a cabo durante los meses de febrero y marzo de 2010, bajo la dirección de la Dra. María Luz Endere (Argentina) y la tutora mexicana, Dra. Martha Carmona Macías (Encargada de la Subdirección Arqueología).

Quería agradecer el buen recibimiento y la predisposición de todos los trabajadores del Museo Nacional de Antropología y especialmente quiero destacar a su directora Dra. Diana Magaloni Merkel; a Sergio González García, Gilda Salgado Manzanares y Laura Filloy (Departamento de Restauración); Rafael Balverde Preciado y Humberto Valentín (Subdirección de Museografía) y Ana Madrigal Limón (Departamento de Archivo). Alejandro González Villaruel (Director de la Subdirección Etnografía), Leopoldo Trejo Barrientos (Departamento Etnografía), Lourdes Garduño Colín (Departamento de Servicios Educativos), Patricio Mejía (Subdirección de Protección de Bienes Culturales), Jorge Rubalcava (Departamento de Promoción Cultural), Juan Martínez Martínez (Subdirección Técnica) y Fernando Ballesteros (Servicio Social).

Especialmente quiero agradecer las largas charlas y discusiones con Roberto Velasco Alonso (Jefe del Departamento de Movimientos de Colecciones), quién ha leído críticamente una versión previa de este artículo, a él y a Sergio González García y Fernando Gómez Castellanos por la información inédita que me facilitaron. Por último, a Pamela Garcés Martínez (auxiliar de Movimiento de Colecciones) por la generosidad y hospitalidad brindada. Ellos, sumados a Francisco del Prado, Priscila Medina, Rodrigo Valentino y Andrea Tetzícatl, hicieron de mi estadía una experiencia inolvidable. Finalmente a los/as evaluadores/as anónimos/as que ayudaron a mejorar este artículo, sin embargo, soy responsable de los conceptos vertidos en el mismo.

\section{Bibliografía}

Arciniega Ávila, H. 2008. La galería de las Sibilas. El Museo Público de Historia Natural, Arqueología e Historia de México. Boletín de Monumentos Históricos, 14: 35-54.

Bonfil Batalla, G. 1987. México Profundo, CIESAS/SEP, México.

Clifford, J. 1993. Coleccionar arte y cultura. Revista de Occidente 141: 19-40.

Coremans, P. 1969. Clima y Microclima. La conservación de los bienes culturales, pp. 31-44. UNESCO.

Cronyn, J. 1990. The Elements of Archaeological Conservation. Routledge, Londres- Nueva York.

Gallegos Téllez Rojo, J. 2008. Los cursos del Museo Nacional. Boletín de Monumentos Históricos, 14: 68-89.
García Blanco, A. 1999. La exposición, un medio de comunicación. Ediciones Akal, Madrid.

García Canclini, N. 1990. Culturas Híbridas. Estrategias para entrar y salir de la modernidad, pp: 140-190, Editorial Grijalbo, México.

Gnecco, C. y C. Langebaek. 2006. (Eds.) Introducción. Contra la tiranía tipológica en Arqueología. Una visión desde Suramérica. Ediciones Uniandes. Bogotá.

González García, S. 2009. La vitrina y la conservación preventiva en el museo. Estudio de un caso: la sala preclásico del museo nacional de antropología". Tesis para optar al título de Licenciado en restauración de bienes muebles. Escuela Nacional de Conservación, Restauración y Museografía "Manuel del Castillo Negrete. Instituto Nacional de Antropología e Historia. Secretaría de Educación Pública.

López Barbosa, F. 2001. Funciones, misiones y gestión de la entidad "museo". La arqueología, la etnografía, la historia y el arte en el Museo. Memorias de los Coloquios Nacionales, pp. 29-39, Museo Nacional de Colombia, Ministerio de Cultura, Bogotá.

Hernández Hernández, F. 1998. Manual de Museología. Editorial Síntesis, España.

Montemayor, E. 2000. Un estudio de público en el Museo Nacional de Antropología. Coordinación Nacional de Museos y Exposiciones, INAH. México. Ms.

Morales Moreno, L. 1994. Orígenes de la museología mexicana, fuentes para el estudio histórico del Museo Nacional, 1780-1940. Departamento de Historia de la Universidad Iberoamericana, México.

Morales Moreno, L. 2007. Museológicas. Problemas y vertientes de investigación en México. Relaciones 111, vol XXVIII: 31-66.

Morales Moreno, L. 2008. Los muros del silencio del Museo Nacional de México, siglo XIX. Boletín de Monumentos Históricos, 14: 5- 34.

Nalda, E. 1998. La arqueología mexicana. Arqueología Mexicana 30:6-13.

Nielsen, A. 2006. Pobres jefes: aspectos corporativos en las formaciones sociales pre-inkaicas de los Andes Circumpuneños. (Eds.) C. Gnecco y C. Langebaek. Contra la tiranía tipológica en Arqueología, pp. 121- 150. Colombia.

Pearce, S. 1990. Archaeological curatorship. Smithsonian Institution Press, Washington D.C. 
Perdigón Castañeda, K. 2004-2005. La conservación preventiva. Elementos a considerar para un diagnóstico. CNCPC-INAH, México.

Pérez Monford, R. 2001. El Museo Nacional como expresión del nacionalismo mexicano. Alquimia 12: 27-32.

Pérez Santos, E. 2000. Estudios de visitantes en museos. Metodología y aplicaciones. Ediciones TREA, España.

Ramírez Vázquez, P. 2008. Museo Nacional de Antropología. Gestación, proyecto y construcción, INAH, México.

Ramírez Vázquez, P.; L. Aveleira; R. Piña Chan; D. Sodi; R. de Robina; A. Caso. 1968. El Museo Nacional de Antropología. Arte, Arquitectura, Arqueología, Etnografía. Editorial Tláloc, México, D. C.

Rico Mansard, L. 2004. Exhibir para educar. Objetos, colecciones y museos de la Ciudad de México (17901910). Ediciones Pomares, Horizontes educativos mexicanos, México.

Rico Mansard, L. 2008. El Museo Nacional de México. Una lucha por los espacios. Boletín de Monumentos Históricos, 14:55-67.

Solís Olguín, F. 2004. Azares y aventuras de las colecciones del Museo Nacional de Antropología. Museo Nacional de Antropología México, Libro Conmemorativo del Cuarenta Aniversario, pp. 59-86, CONACULTA, Equilibrista-Turner, Madrid.

Stanley Price, N., 1995. Excavation and Conservation. (Ed.) Stanley Price, N. Conservation on Archaeological Excavations with particular reference to the Mediterranea area, pp.1-9, ICCROM, Roma.

Stolow, N. 1987. Conservation and exhibitions: packing, transport, storage, and environmental considerations, Buttersworth, Boston.
Trigger, B. 1992. Historia del pensamiento arqueológico. Editorial Crítica. Madrid.

Thomson, G. 1998. El museo y su entorno, editorial Akal, Madrid.

van Mensch, P. 1990. Methodological museology; or, towards a theory of museum practice. (Ed.) Susan Pearce. Objects of Knowledge, New Research in Museum Studies pp. 141-157, The Athlone Press, Londres.

Vázquez Olvera, C. 2005. Alfonso Soto Soria. Museógrafo mexicano. INAH, México.

Velasco Alonso, R. 2009. Contribuciones a la exposición: El imperio azteca en los museos Guggenheim de Nueva York y Bilbao, 2004-2005. Trabajo profesional para obtener el título de Licenciado en Historia. Facultad de Estudios Superiores Acatlán, Universidad Nacional Autónoma de México, México. Departamento de Movimientos de Colecciones, Museo Nacional de Antropología.

Weil, S. 1990. Rethinking the museum. Smithsonian Institution Press. Washington D.C.

Williams, V. y B. Alberti. 2006. (Eds.) Género y Etnicidad en la Arqueología Sudamericana. Serie Teórica 4. Ediciones INCUAPA. Tandil.

Williams, V., B. Ventura, A. Callegari y H. Yacobaccio. 2007. (Eds.) Sociedades Precolombinas Surandinas. Temporalidad, Interacción y Dinámica Cultural del NOA en el Ámbito de los Andes Centro-Sur. Buenos Aires.

\section{Fuentes de archivo}

AHMNA: Archivo Documental del Museo Nacional de Antropología. Actividades que realiza el Departamento de Acción Educativa en los museos que dependen del INAH. Volumen 17083 17/09/1962. Expediente 50 - fs 160-162. 